\title{
Chief Residency Selection in Internal Medicine: Who Is Left Out?
}

\author{
Ryan Johnson, $M D^{\top} \oplus$, Oyinkansola Osobamiro, $\mathrm{MD}^{7}$, Anna Morenz, $M D^{\top}$, \\ Nancy Mugisha, $M D^{1}$, Linda Liu, $M D^{7}$, and Tyler Albert, $M D^{1,2}$
}

'Department of Medicine, University of Washington School of Medicine, Seattle, WA, USA; ${ }^{2}$ Veteran's Affairs Puget Sound Health Care System, Seattle, WA, USA.

Little progress has been made in improving racial, gender, or intersectional diversity within academic internal medicine (IM). Chief Residency fulfills a unique opportunity to target diversity efforts; Chief Residents (CR) are integral in creating an inclusive environment and support system for IM trainees, and the position serves as a steppingstone for future leadership positions within academia. However, the CR selection process often lacks transparency and includes steps that are fraught with bias, thereby disadvantaging underrepresented minority groups from gaining important experience needed to climb the academic ladder. We describe a more standardized selection process that will improve recruitment and selection of more diverse CRs and ultimately improve the recruitment, retention, and promotion of more diverse faculty within academic internal medicine. Key recommendations include an open call for applications, the use of standardized and structured interviews, and the formation of a diverse selection committee to conduct a transparent selection process based on explicitly defined criteria.

J Gen Intern Med 37(5):1261-4

DOI: $10.1007 /$ s11606-021-07364-6

(c) The Author(s) under exclusive licence to Society of General Internal Medicine 2022

\section{INTRODUCTION}

Little progress has been made in diversifying academic internal medicine (IM); only $9.7 \%$ of faculty identify as racially underrepresented in medicine (UiM), grossly underrepresenting the diversity of medical students $(18.1 \%)$, residents $(12 \%)$, and the US population $(31.5 \%) .1,2$ With most UiM faculty working at historically Black institutions or in Puerto Rico, these disparities are further accentuated at many academic institutions. ${ }^{3}$ Similar gaps exist for women; although women matriculate to medical school in similar proportions as men, women remain less likely to advance in academic rank or to leadership positions. ${ }^{4,5}$ Furthermore, the proportion of women faculty identifying as UiM remains stagnant at $13 \%$,

Received June 10, 2021

Accepted December 16, 2021

Published online January 24, 2022 emphasizing the need for improvements in intersectional recruitment. ${ }^{5,6}$ Other areas of much needed attention include transgender and nonbinary physicians, for which data are limited, and people with disabilities, who have historically been excluded from medical training. ${ }^{7,8}$

Chief Residency, a position of honor and prestige within academic IM, is an important pipeline for future leadership positions. ${ }^{9-11}$ Chief Residents (CR) are the outward face of many IM residency programs and play an important role in the education, recruitment, and mentorship of trainees. Acting as resident-faculty liaison provides these early-career physicians the unique opportunity to improve their teaching, leadership, and administration through dedicated mentorship from academic and hospital leadership and is a stepping stone to academic promotion..$^{9,11}$

Although ongoing efforts are dedicated to promoting diversity within academic medicine, ${ }^{12,13}$ there are limited data on CRs or their selection process. Some institutions have created innovative ways to help reduce burnout among UiM residents and thereby increase retention of UiM into faculty positions, such as creating a CR position for Diversity and Inclusion. ${ }^{14}$ While these creative solutions are desperately needed, all CRs should be invested in intentionally dismantling the longstanding oppressive systems that continue to hinder people of color, committed to anti-oppression, and devoted to improving intersectional diversity in medicine. ${ }^{15} \mathrm{We}$ describe how a standardized selection process may improve recruitment and selection of more diverse CRs and ultimately improve the recruitment, retention, and promotion of more diverse faculty within academic IM.

\section{SELECTION PROCESS}

Little data exists on how CRs are selected; it is often an opaque process that varies between residency programs nationwide (Table 1). ${ }^{21}$ Interviews, if they occur, can differ in the questions asked and in the number and academic rank of participants. The decision process may involve hospital or program leadership and may include group discussions, a voting process, or scoring rubrics. Decisions are often based on information that can be fraught with bias resulting from a legacy of cultural stereotyping and exclusion. For example, women or 
Table 1. Published Strategies for Chief Resident Selection Throughout Medicine

\begin{tabular}{ll}
\hline \hline Process & Pitfalls \\
\hline Nominations by $_{\text {residents }}{ }^{6}$ & Popularity is not a proxy for success in the \\
leadership role of a chief resident \\
- Residents are often not given guidance on \\
how to vote based on accomplishments of \\
nominees and qualities sought for the job \\
- There can be variability in who participates \\
in the voting process, which can lead to biased \\
results \\
- Faculty and staff \\
voting \\
residents can be biased \\
- Clinical skills observed on the wards are not \\
necessarily representative of the skills required \\
to be a successful chief resident. \\
- To gather information about residents with \\
whom they may or may not have worked, \\
program directors often gather information via \\
informal discussions with other faculty \\
members. ${ }^{20}$ This may lead to selection based \\
leadership 19
\end{tabular}

residents who identify as UiM can be disadvantaged during a nomination process that depends upon interpersonal relationships. Inter-group social anxiety can lead to racial and ethnic isolation, with members of a particular racial or ethnic group being less likely to seek out interactions with different groups due to anxiety about the interactions. ${ }^{22}$ This can lead to othering of UiM residents and negatively impact the likelihood of being nominated by faculty or peers. Furthermore, assessments of a resident's professionalism, leadership, and communication, attributes valued for $\mathrm{CR}$ candidates, can be affected by faculty and/or trainee gender. ${ }^{23,24}$ Lastly, the descriptive language used in subjective assessments of qualifications can differ by trainees' gender or race, such as Black applicants being less likely to be described with ability keywords such as "outstanding" relative to white applicants. ${ }^{25}$ If existing academic leaders who belong to traditionally privileged groups are selecting future leaders without conscious and intentional methods of countering bias, this vicious cycle will continue to hinder the promotion and success of physicians currently underrepresented in leadership positions.

\section{RECOMMENDATIONS}

Individuals from underrepresented or traditionally excluded groups are disadvantaged in the hiring process for leadership positions in many fields, including within academic IM. ${ }^{5,26-28}$ We propose a series of concrete recommendations to eliminate bias and equitably select CRs (Table 2).

\section{OPEN APPLICATIONS}

Establishing an open and standardized CR application process may improve inclusivity by providing all interested residents the opportunity to apply. This can mitigate any implicit or
Table 2. Recommendations for Chief Resident Selection

\begin{tabular}{|c|c|}
\hline Process & Specific interventions \\
\hline Application & $\begin{array}{l}\text { - Broadly advertise position to all residents } \\
\text { - Create a transparent application process } \\
\text { - Include a clear job description that: } \\
\text { o Avoids use of gendered descriptors (e.g. } \\
\text { "competitive", "strong" or "nurturing", "supportive"), } \\
\text { uses gender neutral or second person pronouns } \\
\text { ("they/them" or "you" rather than "his/her"), and avoids } \\
\text { superlatives such as "best of the best" and "superior".29 } \\
\text { o Avoids culturally biased reference such as "master" or } \\
\text { "Strong/Native English speaker" } \\
\text { o Describes the ideal qualities of a chief resident, } \\
\text { including being committed to advancing equity and } \\
\text { fostering anti-racism in the program }\end{array}$ \\
\hline Interview & $\begin{array}{l}\text { - Programs should seek involvement and visibility of } \\
\text { UiM faculty in the interviewing process } \\
\text { - All interviewers should be required to undergo formal } \\
\text { implicit bias training that includes reflection and } \\
\text { strategies to interrupt bias } \\
\text { - Interviews should include standardized questions with } \\
\text { a grading rubric on diversity, equity, and inclusion to } \\
\text { improve reliability and validity: } \\
\text { o "How have your experiences shaped how you address } \\
\text { and contribute to an equitable, and inclusive training } \\
\text { environment?" } \\
\text { o "How do you approach understanding the perspectives } \\
\text { of colleagues and patients from different backgrounds?" } \\
\text { o "How would you handle a situation where a colleague } \\
\text { was being culturally insensitive, sexist, racist, ableist, or } \\
\text { homophobic?" } \\
\text { o"Tell me about a time when you advocated for } \\
\text { diversity and inclusion in the workplace or health equity } \\
\text { in the community?" }\end{array}$ \\
\hline Selection & $\begin{array}{l}\text { - Form a selection committee of relevant stakeholders } \\
\text { that have undergone implicit bias training } \\
\text { - Place high value on candidates with extracurricular } \\
\text { activities that advance equity, diversity, and inclusion or } \\
\text { resident community well-being that are not traditionally } \\
\text { tangibly recognized (e.g. volunteering for minority } \\
\text { recruitment or mentorship) } \\
\text { - Blind selection committee members to data not } \\
\text { relevant for chief qualities: e.g. USMLE scores, } \\
\text { in-training exam (ITE) scores.1 } \\
\text { - Exclude information that is not available for every } \\
\text { candidate (e.g. personal relationships, word of mouth, } \\
\text { unsolicited faculty input, etc). } \\
\text { - Formally collect resident and faculty input }\end{array}$ \\
\hline
\end{tabular}

explicit bias that occurs during a nomination or direct appointment process. The call for applications should include a clear and detailed job description without cultural or gendered references and should list the ideal qualities desired for potential CRs. ${ }^{24}$ Desired qualifications should include a commitment to advancing equity and fostering anti-racism within the program.

\section{STRUCTURED INTERVIEWS}

Structured interviews, which enhance the objective value of the interview or selection process, are significantly less susceptible to bias as compared to unstructured interviews. ${ }^{32}$ Examples of these strategies include asking all candidates the same questions; asking questions that are situational, behavior-based, or focused on job knowledge; rating each answer on scales tailored for each question; using multiple 
interviewers and the same interviewers for all candidates; and providing extensive interviewer training. ${ }^{33}$

Applying this strategy to CR interviews is paramount to mitigate biases that can arise in the interview setting. Residency programs should be intentional in selecting interviewers and seek involvement from underrepresented faculty in the interviewing process, while also appropriately valuing, protecting, and compensating their time with the acknowledgment of the expectations and magnitude of emotional labor expected from these faculty members. ${ }^{34}$ All interviewers should be required to undergo formal and validated implicit bias training that includes concrete strategies for interrupting bias. ${ }^{35}$ Interviews should be structured as much as possible and use standardized questions to maximize objectivity and improve reliability, validity, and equity. ${ }^{28,36}$ Examples of standardized questions to assess candidates' commitment to equity, diversity, and inclusion are provided in Table 2.

\section{TRANSPARENT SELECTION PROCESS}

The selection process should be transparent, all-inclusive, and value a commitment to health equity and anti-oppression. A formal selection committee should be formed and consist of relevant stakeholders (e.g., program faculty, hospital leadership, current/former CRs) and those involved in making final decisions. Committee members should explicitly define selection criteria and review applicants using an objective scoring system that considers equitably obtained information from each applicant. Information not available for all candidates, such as word of mouth or unsolicited faculty input, should be excluded to minimize bias. Resident or faculty feedback about candidates should be considered and formally and systematically collected (e.g., online surveys).

Most importantly, the committee should reevaluate any preconceived notions about who will be successful as a CR. Opinions regarding the ideal qualities of CRs may differ, with leadership and organizational skills being important to faculty and approachability and listening skills being important to trainees. ${ }^{24}$ Selection committees should prioritize candidates with the skills and experience to advocate for a diverse group of residents. Specific interview questions should help elucidate which applicants are equipped with these skills (Table 2).

\section{CONCLUSION}

We must prioritize diversity and equity throughout our mission and practice as academic physicians, especially given the unjust and unacceptable health inequities born by Black, Indigenous, queer, and disabled communities and communities of color due to generations of structural oppression and violence. This involves promoting diversity and minimizing bias among academic and hospital leadership. A more diverse pool of Chief Residents will create an environment in which UiM trainees feel welcome, have mentorship from those of similar backgrounds, and are inspired to become academic leaders in the future. It is one step of many in fixing a broken system.

Acknowledgements: The authors would like to thank Dr. Rudolph Rodriguez for his mentorship and support on this project.

Corresponding Author: Ryan Johnson, MD; Department of Medicine, University of Washington School of Medicine, Seattle, WA, USA (e-mail: rmj16@uw.edu).

\section{Declarations:}

Conflict of Interest: The authors declare that they do not have a conflict of interest.

\section{REFERENCES}

1. Ogunwole SM, Dill M, Jones K, Golden SH. Trends in Internal Medicine Faculty by Sex and Race/Ethnicity, 1980-2018. JAMA Netw Open. 2020;3(9):e2015205. https://doi.org/10.1001/jamanetworkopen.2020. 15205.

2. Report on Residents. Association of American Medical Colleges. 2020. Website https://www.aamc.org/data-reports/students-residents/interactive-data/report-residents/2020/table-b5-md-residents-race-ethnicity-and-specialty.

3. Peek ME, Kim KE, Johnson JK, Vela MB. "URM Candidates Are Encouraged to Apply": A National Study to Identify Effective Strategies to Enhance Racial and Ethnic Faculty Diversity in Academic Departments of Medicine. Academic Medicine. 2013;88:405-412.

4. Lautenberger DA, Dandar VM. "The State of Women in Academic Medicine: Exploring Pathways to Equity 2018-2019." Association of American Medical Colleges. https://store.aamc.org/downloadable/ download/sample/sample_id/330/ Accessed April 13, 2021.

5. Richter KP et al. "Women Physicians and Promotion in Academic Medicine." N Engl J Med 2020;383:2148-57. 10.1056/ NEJMsa1916935.Alpert J, Levenson S, Osman C, James S. Does being a chief resident predict leadership in pediatric careers? Pediatrics 2000; 105:984-8.

6. Eckstrand $\mathrm{KL}$, et al. "The Priority of Intersectionality in Academic Medicine." Acad Med. 2016;91:904-907. https://doi.org/10.1097/ ACM.0000000000001231

7. Cook, TE, et al. "Gendered Expectations: Strategies for Navigating Structural Challenges in Support of Transgender and Nonbinary Trainees in Academic Medicine." Acad Med. 2020;95:704-709. First published online February 11, 2020. https://doi.org/10.1097/ACM. 0000000000003202

8. Meeks LM, Stergiopoulos E, Petersen KH. Institutional Accountability for Students With Disabilities: A Call for Liaison Committee on Medical Education Action. Acad Med. 2021.

9. Singh D, McDonald FS, Beasley BW. Demographic and Work-Life Study of Chief Residents: A Survey of the Program Directors in Internal Medicine Residency Programs in the United States. J Grad Med Educ. 2009;1(1): 150-154.

10. Alpert J, Levenson S, Osman C, James S. Does being a chief resident predict leadership in pediatric careers? Pediatrics. 2000;105:984-8.

11. Dick, John. Chief resident year as stepping stone to attending academic hospitalist. Journal Of Hospital Medicine. 2011;6(9):550-551. https:// doi.org/10.1002/jhm.963.

12. Merchant JL, Omary MB. Underrepresentation of Underrepresented Minorities in Academic Medicine: The Need to Enhance the Pipeline and the Pipe. Gastroenterology 2010;138(1):19-26.e3

13. American Indians' Growing Presence In The Health Professions. Health Affairs 2021;40(2):192-96 10.1377/hlthaff.2020.02289

14. Londono Tobon A, Budde KS, Rohrbaugh RM. A Novel Approach to Fostering Diversity in Graduate Medical Education: Chief Residents for Diversity and Inclusion. Academic Psychiatry 2019;43(3):344-45 https://doi.org/10.1007/s40596-019-01055-5

15. Thatipelli S, Osude N, Youmans QR. Towards Inclusion: a Guidebook for Championing Diversity for Internal Medicine Chief Medical Residents. Journal of General Internal Medicine 202 1;36(6):1761-64 https://doi.org/10.1007/s11606-021-06782-w[published Online First: Epub Date]|. 
16. Siegel M. Choosing our Chief Residents. Secondary Choosing our Chief Residents 2016. https://medicine.yale.edu/news-article/14043/.

17. Hafner JW, Gardner JC, Boston WS, Aldag JC. The chief resident role in emergency medicine residency programs. West $J$ Emerg Med 2010;11(2): 120-5

18. Chertoff JD. Staff Meetings/Choosing the Chief Resident. Journal of the American College of Radiology 2011;8(5):360-61 https://doi.org/10. 1016/j.jacr.2010.05.014[published Online First: Epub Date]|.

19. Susman, J; Gilbert, C Family medicine residency directors' perceptions of the position of chief resident, Academic Medicine: March 1992 Volume 67 - Issue 3 - p 212-3

20. Ivany CG, Hurt PH. Enhancing the effectiveness of the psychiatric chief resident. Academic psychiatry : the journal of the American Association of Directors of Psychiatric Residency Training and the Association for Academic Psychiatry. 31(4):277-280. 10.1176/appi.ap.31.4.277

21. Deane K, Ringdahl E. The family medicine chief resident: a national survey of leadership development. Fam Med 2012;44(2):117-20.

22. Plant EA, Devine PG. The antecedents and implications of interracial anxiety. Pers Soc Psychol Bull. 2003;29(6):790-801. https://doi.org/10. $1177 / 0146167203029006011$

23. Klein R, Ufere NN, Rao SR, et al; Gender Equity in Medicine workgroup. Association of gender with learner assessment in graduate medical education. JAMA Netw Open. 2020;3:e2010888.

24. Turner J, Litzau M, Mugele J, Pettit K, et al. Qualities Important in the Selection of Chief Residents. Cureus. 2020;12(4):e7580.

25. Ross DA, Boatright D, Nunez-Smith M, Jordan A, et al. Differences in words used to describe racial and gender groups in Medical Student Performance Evaluations. PLOS ONE. 2017;12(8): e0181659.

26. Brecher E, Bragger J, Kutcher E. The Structured Interview: Reducing Bias Toward Job Applicants with Physical Disabilities. Employ Respons Rights J. 2006; 18: 155-170.

27. Huffcutt AI, Roth PL. Racial Group Differences in Employment Interview Evaluations. Journal of Applied Psychology. 1998;83(2):179-189.
28. Bohnet I. How to Take the Bias Out of Interviews. Harvard Business Review. 2016. https://hbr.org/2016/04/how-to-take-the-bias-out-ofinterviews.

29. Gaucher D, Friesen J, Kay AC. Evidence that gendered wording in job advertisements exists and sustains gender inequality. Journal of personality and social psychology. 2011;101:109.

30. Newman Mason K. 8 Interview Questions on Diversity and Inclusion Every Job Seeker Should Be Able to Answer. The Muse. https://www. themuse.com/advice/diversity-inclusion-interview-questions-answersexamples. Published August 13, 2020. Accessed May 10, 2021.

31. Nehemiah A, Roberts SE, Song Y, Kelz RR, Butler PD, Morris JB, Aarons CB. Looking Beyond the Numbers: Increasing Diversity and Inclusion Through Holistic Review in General Surgery Recruitment. J Surg Educ. 2020 Sep 16:S1931-7204(20)30348-2. 10.1016/ j.jsurg.2020.08.048. Epub ahead of print.

32. Aamodt, Mike G., et al. "Do Structured Interviews Eliminate Bias? A Meta-Analysis of Interview Structure.” PsycEXTRA Dataset, 2006, https://doi.org/10.1037/e518572013-156.

33. Campion MA, Palmer DK, Campion JE. A Review of Structure in the Selection Interview. Personnel Psychology. 2006;50(3):655-702.

34. Campbell KM. The Diversity Efforts Disparity in Academic Medicine. Int J Environ Res Public Health. 2021;18.

35. Gino F, Coffman $\mathbf{K}$. Unconscious Bias Training That Works: Increasing awareness isn't enough. Teach people to manage their biases, change their behavior, and track their progress. 2021. Accessed November 5, 2021. https://hbr.org/2021/09/unconscious-bias-training-that-works.

36. Levashina J, Hartwell CJ, Morgeson FP, Campion MA. The Structured Employment Interview: Narrative and Quantitative Review of the Research Literature. Personnel Psychology 2014;67(1):241-93 https://doi. org/10.1111/peps. 12052

Publisher's Note: Springer Nature remains neutral with regard to jurisdictional claims in published maps and institutional affiliations. 